\title{
FEMINISMO NEGRO ESTADUNIDENSE E SUA CINJVISIBILIDADE NO CENÁRIO BRASILEIRO: QUESTÕES DE TRADUÇÃO
}

\author{
BLACK AMERICANFEMINISM AND ITS IINJVISIBILITY IN BRAZILIAN SCENARIO: TRANSLATION ISSUES
}

\section{RESUMO}

Este artigo visa a abordar a tradução, no contexto brasileiro, de obras e textos nãoficcionais de intelectuais afro-americanas que discutem questões de gênero e raça. Primeiramente, apresenta-se uma discussão sobre feminismo negro no âmbito dos Estados Unidos, a partir do trabalho de pensadoras como Angela Davis, bell hooks e Patricia Hill Collins. Em seguida, é proposto um breve panorama sobre o que tem sido traduzido no Brasil em relação à escrita das autoras em questão, com informações como títulos das obras e textos traduzidos, anos de publicação, nomes dos/as tradutores/as, editoras e periódicos envolvidos e títulos e anos das obras e textos no contexto de partida. Posteriormente, são feitas reflexões sobre esse cenário, no qual ainda prevalece pouca visibilidade da produção das autoras citadas, especialmente em relação ao grande mercado editorial brasileiro. Como arcabouço teórico, são utilizados os trabalhos de Lefevere (1992), Toury (1995), Collins (2000), entre outros.

Palavras-chave: Feminismo negro estadunidense. Tradução. Textos não-ficcionais.

\begin{abstract}
This article aims to address the translation, in the Brazilian context, of nonfiction works and texts by African-American women intellectuals who discuss gender and race issues. Firstly, there is a discussion of Black feminism in the United States, considering the work of scholars such as Angela Davis, bell hooks and Patricia Hill Collins. Secondly, a brief overview on what has been translated in Brazil regarding the writings of the authors in question is presented. This overview includes information such as the titles of translated works and texts, the years of publication, the names of translators, the publishers and journals involved and the titles and years of works and texts in the source context. Subsequently, reflections on that scenario, in which there is still little visibility of the production of the referred authors, especially in relation to the mainstream Brazilian publishers, are proposed. As theoretical framework, the works of Lefevere (1992), Toury (1995), Collins (2000), among others, are used.
\end{abstract}

Keywords: Black American feminism. Translation. Nonfiction texts.

Luciana de Mesquita Silva

Centro Federal de Educação Tecnológica Celso Suckow da Fonseca (CEFET/RJ), Brasil. E-mail: luciana. cefetrj@gmail.com 


\section{Primeiras palavras}

A proposta deste artigo é um desdobramento de minha comunicação na mesa redonda "Perspectivas sobre tradução e gênero: um olhar sobre os trabalhos de mulheres tradutoras no contexto brasileiro", ocorrida no âmbito do IV Colóquio Internacional de Literatura e Gênero, realizado de 5 a 7 de setembro de 2018, na Universidade Estadual do Piauí, em Teresina-PI. Nessa mesa redonda, composta por mim e pelos pesquisadores Dennys Silva-Reis (UnB) e Fabíola do Socorro Figueiredo Reis (UNIFAP), utilizamos como referência os contextos literário e cultural brasileiros para discutir possíveis articulações entre os Estudos da Tradução e os Estudos de Gênero, por meio de questões como o papel de mulheres tradutoras, os diferentes gêneros traduzidos por elas, as estratégias tradutórias adotadas e as contribuições que elas têm trazido para os/as leitores/as através de suas traduções. Para tanto, tomamos como base as ideias de Lefevere (1992), segundo o qual a tradução é uma reescrita que exerce grande poder sobre a construção das imagens de um/a autor/a, de uma obra e de uma cultura, e de Bassnett (1992), que propõe o seguinte pensamento:

Se nós aceitamos que o/a tradutor/a não é, e nunca poderia ser, um filtro transparente pelo qual o texto passa, mas sim uma fonte muito poderosa de energia criativa transitória (e essa é a premissa fundamental dos intelectuais vinculados aos Estudos da Tradução), então, pensando em termos de gênero, o/a tradutor/a serve para aumentar a conscientização das complexidades textuais tanto no papel do/a escritor/a, quanto no do/a leitor/a. (Bassnett, 1992: 70, tradução minha) ${ }^{1}$

Na minha comunicação, especificamente, procurei aliar os Estudos da Tradução não só a questões de gênero, como também de raça, já que as ligações entre esses distintos campos de estudo fazem parte da minha trajetória acadêmica, incluindo projetos de pesquisa, apresentação de trabalhos em congressos e publicação de artigos em periódicos científicos, e profissional, já que atuo como docente em um programa de pós-graduação interdisciplinar, o Mestrado em Relações Étnico-Raciais do CEFET/RJ. Nesse contexto, desde 2016, tenho ministrado a disciplina "Literaturas afro-americana e afro-brasileira em contextos de tradução", cujo objetivo é fazer uma introdução aos Estudos da Tradução, abordando aspectos linguísticos, culturais e ideológicos, bem como levantar reflexões sobre a tradução de literaturas da diáspora negra, especialmente a literatura afro-brasileira em tradução nos Estados Unidos e a literatura afro-americana em tradução no Brasil.

1 "If we accept that the translator is not, and never could be, a transparent filter through which a text passes, but is rather a very powerful source of creative transitional energy (and this is the fundamental premise of Translation Studies scholars), then thinking in terms of gender serves to heighten awareness of textual complexities in the roles of both writer and reader." 
Com relação à literatura afro-americana traduzida no Brasil, que dialoga com a proposta do presente artigo, de acordo com Álvaro Hattnher em "Presença de autores afro-americanos no Brasil: as traduções" (1998), o primeiro texto afro-americano traduzido para o português brasileiro foi a autobiografia de Booker T. Washington Up from Slavery (1901), lançado no Brasil em 1940. Com o título de Memórias de um negro, esse livro de Washington foi traduzido por Graciliano Ramos e publicado pela Companhia Editora Nacional. No campo da poesia, há um pequeno número de autores representados, e seus poemas costumam ser encontrados de forma dispersa, em diferentes antologias. Entre eles estão Langston Hughes, LeRoi Jones e Claude McKay, sendo que Hughes é o mais traduzido.

Quanto aos romances, esse é o gênero que predomina nas traduções, e fatores comerciais exercem um papel preponderante nesse aspecto. Segundo Hattnher (1998:30), "a prosa tem, inegavelmente, maior penetração e aceitação entre o público leitor brasileiro”. A primeira tradução de um romance afro-americano no Brasil foi a de Native Son (1940), de Richard Wright, realizada por Monteiro Lobato e publicada em 1941 com o título de Filho nativo: tragédia de um negro americano. Outros autores como Chester Himes, James Baldwin e Alex Haley, além das escritoras Alice Walker, Maya Angelou e Toni Morrison, também têm tido obras de sua autoria publicadas no Brasil. É o caso, por exemplo, dos livros A cor púrpura (2009), tradução de The Color Purple (1982), de Alice Walker, realizada por Betulia Machado, Peg Bodelson e Maria José Silveira e publicada pela editora José Olympio e, mais recentemente, Mamãe $\mathcal{E}$ eu $\mathcal{E}$ mamãe (2018), tradução de Mom $\mathcal{E}$ Me $\mathcal{E}$ Mom (2013), de Maya Angelou, feita por Ana Carolina Mesquita e lançada pela editora Rosa dos Tempos. Quanto à literatura de Toni Morrison, foram publicados no Brasil, até o momento, dez de seus onze romances: O olho mais azul (2003), A canção de Solomon (1977), Pérola negra (1987), Amada (1989/1993 e 2007/2011/2018), Jazz (1992/2009), Paraíso (1998), Amor (2005), Compaixão (2009), Voltar para casa (2016) e Deus ajude essa criança (2018). Ou seja, apenas Sula (1973) não foi traduzido. Por outro lado, Beloved e Jazz receberam diferentes traduções e edições.

Segundo Lauro Maia Amorim, a tradução da literatura afro-americana no Brasil se configura de forma peculiar, visto que "não representa necessariamente a veiculação de uma literatura estritamente marginal, nem propaladamente hegemônica" (Amorim, 2012: 113). Dessa forma, em nosso país, a literatura afroamericana poderá ser vista sob diferentes perspectivas: como representativa da literatura estadunidense em geral ou como produto de um campo literário focado em questões raciais, principalmente levando-se em consideração a origem étnica dos/ as seus/suas autores/as. No caso de Alice Walker e Toni Morrison, por exemplo, é importante ressaltar pontos como estes: o livro The Color Purple inspirou um filme com um mesmo título dirigido por Steven Spielberg, que acabou sendo conhecido pelo público em geral no Brasil na década de 80 do século XX, e a tradução brasileira do livro tem escrito em sua capa "vencedor do prêmio Pulitzer". Isso também ocorre, de certa forma, em traduções de livros de Toni Morrison no Brasil como Amada (2007), que apresenta em sua capa a frase "o melhor livro de ficção norte-americano dos 
últimos 25 anos" e faz parte da coleção Prêmio Nobel, da Companhia das Letras, a qual reúne obras de autores que ganharam o Prêmio Nobel de Literatura. Toni Morrison, nesse caso, foi agraciada com o Nobel em 1993, tendo sido a primeira mulher negra - e até os dias de hoje a única - a conquistar essa importante premiação no campo literário. Além disso, no que diz respeito a $M o m \mathcal{E} M e \mathcal{E} M o m$, uma autobiografia que retrata a relação entre Maya Angelou e sua mãe Vivian Baxter, sua tradução no Brasil foi publicada pela Rosa dos Tempos, que se define como a primeira editora feminista brasileira.

Diante desse cenário, surge a seguinte reflexão: Será que se Alice Walker e Toni Morrison não fossem autoras de sucesso no contexto estadunidense e em âmbito mundial, elas teriam seus romances selecionados por grandes editoras para serem traduzidos no Brasil? E, no caso específico de The Color Purple, se o romance não tivesse inspirado um filme dirigido por Spielberg, ele teria sua tradução cogitada para ser feita e lançada no contexto brasileiro? Se a Rosa dos Tempos não tivesse como propósito a divulgação de obras feministas, Mom $\mathcal{E}$ Me $\mathcal{E}$ Mom teria sido escolhido para ser publicado? E quanto aos gêneros a que esses livros pertencem: o fato de serem narrativas em prosa pode ter sido determinante na decisão de traduzi-los?

Como base para tais questionamentos estão alguns pressupostos teóricos como a teoria dos polissistemas e os Estudos Descritivos da Tradução. A teoria dos polissistemas foi desenvolvida por Itamar Even-Zohar na década de 1970 e aprimorada nos anos de 1990. Segundo o autor, o acréscimo do prefixo "poli" à palavra "sistema" teve como objetivo enfatizar a multiplicidade de relações entre diferentes sistemas literários e extraliterários, demonstrando, com isso, que uma obra literária não deve ser estudada de forma isolada. Sendo assim, um polissistema "[...] é um sistema múltiplo, um sistema com vários sistemas que se cruzam e se sobrepõem parcialmente, utilizando opções diferentes simultaneamente, mas funcionando como um conjunto estruturado, cujos membros são interdependentes" (Even-Zohar, 2005: 3, tradução minha) ${ }^{2}$. Nessa concepção, fenômenos como cultura, língua e literatura são vistos como sistemas heterogêneos e dinâmicos que se interconectam e são organizados hierarquicamente.

Uma das características da teoria dos polissistemas é a análise das relações entre os diversos sistemas, permitindo uma compreensão mais abrangente de suas configurações. Por exemplo, no estudo da imagem considerada "oficial" de uma cultura também são levadas em conta as culturas "não-oficiais" e, no estudo da variante culta, são abordadas outras variedades linguísticas. Essas estratégias se vinculam à hipótese polissistêmica de que julgamentos de valor - a partir dos quais o que se propõe como "oficial" ou "culto" geralmente é visto como superior em comparação a outras formas de língua ou cultura - não são usados como critérios para uma seleção apriorística dos objetos de estudo. Outro ponto que merece ser destacado tem a ver com a escolha dos objetos de estudo: ao se tomar como referência a teoria dos polissistemas, há

2 "[...] a multiple system, a system of various systems which intersect with each other and partly overlap, using concurrently different options, yet functioning as one structured whole, whose members are interdependent". 
a possibilidade de dar visibilidade a sistemas frequentemente desconsiderados ou relegados a uma condição de marginalidade em relação àqueles vistos notadamente como canonizados e, por esse motivo, geralmente mais valorizados.

No contexto de suas teorias, Even-Zohar levantou discussões em torno do papel da tradução na literatura, tópico frequentemente ignorado pelos demais teóricos literários à sua época. Com isso, ele ampliou as formas de se pensar a seleção de textos para serem traduzidos, bem como a função da literatura traduzida dentro de um polissistema específico. De acordo com Mark Shuttleworth, em "Polysystem Theory" (1998), em tal abordagem não-prescritiva, os textos traduzidos deixam de ser associados a fenômenos isolados e passam a ser considerados produtos modelados conforme o polissistema literário de chegada (Shuttleworth, 1998: 178). Dessa forma, lançando luz sobre as características inerentes a cada cultura, Even-Zohar apresentou uma visão de tradução não como uma atividade meramente linguística e realizada em um vácuo, mas sim como uma prática histórica e culturalmente contextualizada. Maria Tymoczko, no livro Enlarging Translation, Empowering Translators (2007), reitera esse pensamento ao afirmar que Even-Zohar trouxe à tona "[...] a noção de tradução como parte de um sistema literário, que, por sua vez, está inserido em outros sistemas culturais [...] colocando a tradução em contextos culturais mais amplos do que aquilo que havia sido proposto anteriormente" (Tymoczko, 2007: 40, tradução minha)3.

Ideias como as de Even-Zohar contribuíram para fundamentar a teorização de Gideon Toury no âmbito da abordagem descritivista dos Estudos da Tradução. Conforme o autor, no livro Descriptive Translation Studies and Beyond (1995), a tradução é um fato característico da cultura que recebe a tradução (cultura de chegada ou cultura-meta), que engloba desde a seleção de determinados textos a serem traduzidos (ou vistos como traduções), os procedimentos seguidos pelo/a tradutor/a e a posição que as traduções ocupam em determinada conjuntura cultural. Além disso, existem regularidades nas relações entre o lugar sistêmico ocupado pela tradução no polo de chegada (função), o seu formato final (produto) e as estratégias tradutórias adotadas (processo). Na medida em que a função de uma tradução na cultura-meta é determinante em todas as etapas do processo tradutório, visto que objetiva atender a demandas ou preencher lacunas em um contexto literário e cultural específico, determinadas características do texto-fonte são conservadas na tradução não porque são intrinsecamente importantes, mas sim devido à sua relevância na cultura receptora (Toury, 1995: 12). Somam-se ao pensamento de Toury as visões de Susan Bassnett e André Lefevere de que a tradução é uma forma de reescrita e “[...] como todas as (re)escritas nunca é inocente. Há sempre um contexto em que a tradução ocorre, sempre uma história da qual um texto emerge e para a qual um texto é transposto" (Bassnett \& Lefevere, 1990: 11, tradução minha4). Sendo assim,

3 “[...] the notion of translation as part of a literary system, with the literary system in turn embedded in other cultural systems [...] thus setting translation in much broader cultural contexts than had been done earlier".

4 "[...] like all (re)writings [translation] is never innocent. There is always a context in which the translation takes place, always a history from which a text emerges and to which a text is transposed." 
para Bassnett e Lefevere, a tradução é um processo que ultrapassa a transposição de sentidos de uma língua para outra, visto que nele estão envolvidos aspectos históricos, culturais, sociais, ideológicos e econômicos.

Além disso, Lefevere (1992) aponta para o fato de a tradução ser realizada a serviço do poder, na medida em que está submetida a mecanismos de controle internos ou externos que atuam no sistema literário e desempenham um papel essencial na construção do produto final. No que diz respeito aos mecanismos de controle internos, eles são representados por reescritores/as - tradutores/as, críticos/ as, professores/as de literatura e revisores/as - os/as quais tendem a manipular as obras literárias de acordo com a poética e a ideologia dominantes em dada cultura, em dado momento histórico. Os mecanismos de controle externos, por sua vez, estão ligados à patronagem. Trata-se de indivíduos ou instituições com autoridade para regular a produção, a divulgação, a leitura e a reescrita da literatura. Entre eles se encontram partidos políticos, associações religiosas, editoras e veículos midiáticos. Além disso, a patronagem é constituída por um componente ideológico, que atua restringindo a escolha e o desenvolvimento tanto da forma quanto do conteúdo; um componente econômico, por meio do financiamento dos trabalhos de escritores/as e reescritores/as e um componente de status, a partir do qual submeter-se à patronagem significa integrar-se a um grupo e a um estilo de vida.

Retornando à literatura afro-americana traduzida no Brasil, com relação aos ensaios - gêneros não-ficcionais - eles têm pouca representatividade em nosso país pela via da tradução. Nas palavras de Hattnher, esse tipo de produção "parece não despertar o interesse dos editores brasileiros” (Hattnher, 1998: 305). Mais de vinte anos se passaram após a publicação do artigo em questão, mas pouco parece ter mudado em relação ao quadro abordado por Hattnher. Entre alguns exemplos existentes no Brasil podem ser mencionados Os negros na América Latina (2014), do professor de Harvard e intelectual Henry Louis Gates Jr., traduzido por Donaldson M. Garschagen e publicado pela Companhia das Letras e Entre o mundo e eu (2016), do jornalista Ta-Nehisi Coates, traduzido por Paulo Geiger e também publicado pela mesma editora. E com relação às obras de intelectuais afro-americanas que tratam de questões de gênero e raça? O que tem sido traduzido e publicado no polissistema literário brasileiro?

Considerando-se o cenário apresentado, o presente artigo tem como foco a abordagem da tradução de textos não-ficcionais de pensadoras afro-americanas, tais como June Jordan, Audre Lorde, Angela Davis, bell hooks e Patricia Hill Collins. Para tal, primeiramente, será realizada uma breve discussão sobre feminismo negro estadunidense. Em seguida, será elaborado um breve panorama de obras completas e textos, em seus mais diversos gêneros não-ficcionais, escritos por essas intelectuais, que têm sido traduzidos e publicados no Brasil. Nesse sentido, serão disponibilizados dados como nomes das autoras, anos de publicação das obras e dos textos traduzidos, títulos, nomes dos/as tradutores/as, locais de publicação, editoras e periódicos acadêmicos, bem como títulos e anos de publicação da primeira edição dos livros ou textos no contexto de partida. Posteriormente, nessa mesma seção, será apresentada 
uma reflexão sobre as informações encontradas, com o objetivo de compreender o cenário relativo à tradução de escritas das autoras em questão.

\section{“Não sou eu uma mulher?” Algumas considerações sobre feminismo negro no contexto estadunidense}

A pergunta que abre o título desta seção é uma tradução de parte do discurso de Sojourner Truth ("Peregrina da verdade"), proferido em 1851, em uma convenção de mulheres em Akron, Ohio, nos Estados Unidos. Nascida na condição de escravizada em Swartekill, Nova York, no ano de 1797, ela fugiu em busca de sua liberdade em 1826 e chegou à cidade de Nova York em 1829. Em 1843, Truth decidiu sair de Nova York e, um ano depois, associou-se à organização abolicionista Northampton Association of Education and Industry, em Massachusetts. Alguns anos mais tarde, começou a se aproximar do movimento de direitos das mulheres.

Quanto à convenção mencionada, nela estavam sendo discutidas questões como o sufrágio feminino. Depois da fala de um homem que defendeu a ideia de que as mulheres eram fisicamente inferiores e, por esse motivo, fracas para desempenhar trabalhos braçais, além de totalmente dependentes dos homens para realizarem atividades cotidianas como pular uma poça d'água ou entrar em uma carruagem, Truth, a única mulher negra e ex-escravizada presente na convenção, surpreendeu a todos ao levantar a sua voz. Isso ocorreu mesmo após as próprias mulheres ligadas à convenção tentarem impedi-la de falar, temendo que ela deslocasse o foco das reivindicações de direito ao voto. Tal fato por si só ilustra a predominância do racismo dentro do movimento sufragista feminino. Um trecho das palavras de Truth, nesse contexto, encontra-se em Mulheres, raça e classe (2016), de Angela Davis:

Arei a terra, plantei, enchi os celeiros, e nenhum homem podia se igualar a mim! Não sou eu uma mulher? Eu podia trabalhar tanto e comer tanto quanto um homem - quando eu conseguia comida - e aguentava o chicote da mesma forma! Não sou eu uma mulher? Dei à luz treze crianças e via maioria ser vendida como escrava e, quando chorei em meu sofrimento de mãe, ninguém, exceto Jesus, me ouviu! Não sou eu uma mulher? (Truth apud Davis, 2016: 71)

O discurso de Truth trouxe uma lição para os homens, que defendiam a supremacia masculina, bem como para as mulheres do movimento feminista, uma vez que lançou luz ao fato de nem todas as mulheres serem brancas e terem os privilégios de pertencerem a uma camada social favorecida. Ao relatar sua própria experiência de vida, Truth desconstruiu ideias como as de fragilidade e de submissão, geralmente vinculadas às mulheres, e demonstrou que ser negra e pobre, diferentemente das demais mulheres naquela convenção, não excluía sua condição 
de mulher e, do mesmo modo, não tornava suas reivindicações menos legítimas. Segundo Ribeiro (2017), "esse discurso de Truth, ainda no século XIX, já evidencia um grande dilema que o feminismo hegemônico viria a enfrentar: a universalização da categoria mulher" (Ribeiro, 2017: 21). Em Sister Outsider, a escritora Audre Lorde já apontava para essa observação feita por Ribeiro, destacando o fato de que ignorar as diferenças entre as mulheres constitui-se como uma grave ameaça ao movimento feminista coletivo:

Como as mulheres brancas ignoram seu privilégio inerente de branquitude e definem mulher exclusivamente com base em suas próprias experiências, entãoas mulheres de cor ${ }^{5}$ são transformadas em "outras", as estranhas cuja experiência e tradição é muito "alheia" para ser compreendida. [...] Negar o reconhecimento das diferenças torna impossível enxergar os diversos problemas e perigos que nós enfrentamos como mulheres. (Lorde, 2007: 115116, tradução minha) ${ }^{6}$

Nesse caso, pode-se observar que há uma tendência por parte das feministas brancas em insistir nas opressões relativas a gênero, deixando de lado outros tipos de opressão, tais como a de raça.

É importante ressaltar que, na década de 1980, muitas mulheres de cor estadunidenses ligadas a movimentos sociais passaram a ingressar na academia seja como estudantes de pós-graduação, seja como docentes. No caso de mulheres negras, elas acabaram levando ideias do feminismo negro para a universidade e contribuíram para os estudos de raça, gênero e classe. Segundo a cientista social e professora universitária Patricia Hill Collins, nesse cenário surgiram importantes publicações:

As principais obras de mulheres negras afro-americanas, que estabeleceram as bases para o que veio a ser conhecido como interseccionalidade, incluem Civil Wars, de June Jordan (Jordan, 1981); o clássico Sister Outsider (Lorde, 1984) de Audre Lorde; e o inovador Mulheres, Raça e Classe de Angela Davis (Davis, 1981). (Collins, 2017: 9)

\footnotetext{
5 "Mulheres de cor" está sendo utilizado como tradução de women of color que, no contexto dos Estados Unidos, refere-se a mulheres de ascendência asiática, latino-americana, indígena e africana. Mesmo que no Brasil possam ser encontrados termos como "mulheres não-brancas", "mulheres de minorias étnicas" e "mulheres racializadas" como traduções de women of color, neste artigo optou-se pelo uso de "mulheres de cor" com o objetivo de ressignificar positivamente um termo historicamente considerado ofensivo, assim como fez o movimento negro brasileiro nos anos 40 e 50 do século XX. Para mais informações sobre esse assunto, ver o artigo "Quem nomeou essas mulheres "de cor"? Políticas feministas de tradução que mal dão conta das sujeitas negras traduzidas", de Tatiana Nascimento, publicado na revista Translatio (2017), n. 13, p. 127-142.

6 "As white women ignore their built-in privilege of whiteness and define woman in terms of their own experience alone, then women of Color become "other," the outsider whose experience and tradition is too "alien" to comprehend. [...] Refusing to recognize difference makes it impossible to see the different problems and pitfalls facing us as women."
} 
Com relação às autoras citadas por Collins, June Jordan (1936-2002) foi poeta, professora, ativista no movimento feminista e pelos direitos civis. Entre suas publicações encontram-se Who Look at Me (1969), New Days: Poems of Exile and Return (1974), On Call: Political Essays (1985), Affirmative Acts: Political Essays (1998) e Some of Us Did Not Die: New and Selected Essays (2002). Quanto a Civil Wars (1981), trata-se de uma coletânea de ensaios na qual Jordan discute temas como direitos das crianças, Estudos Afro-Americanos, sexualidade, linguagem e poder. Sobre esse último tópico, ela afirma: "Como poeta e escritora negra, eu odeio palavras que cancelam o meu nome e a minha história e a liberdade sobre o meu futuro: eu odeio as palavras que condenam e recusam a língua do meu povo nos Estados Unidos" (Jordan, 1981: 68, tradução minha7). Segundo Collins (2017), Jordan se engajou na luta pela liberdade não só para os afro-americanos, como também para outros grupos de pessoas submetidas a sistemas de opressão, uma vez que, para ela, as mulheres negras nunca seriam totalmente livres se apenas lutassem pelos seus próprios interesses.

No que diz respeito a Audre Lorde (1934-1992), ela costumava se identificar como "negra, lésbica, mãe, guerreira e poeta"8 e abordar temas como raça, gênero e sexualidade em suas obras. Ao mesmo tempo em que contribuiu para os campos de Estudos Feministas, Estudos Críticos de Raça e teoria queer, ela tratava de assuntos pessoais e políticos em sua escrita, buscando celebrar as diferenças entre as pessoas. Estas são algumas de suas coletâneas de poemas: The First Cities (1968), Cables to Rage (1970) e From a Land Where Other People Live (1972). Além disso, ela escreveu a obra The Cancer Journals (1980), em que discorre sobre questões feministas ao relatar sua luta contra um câncer de mama; o romance Zami: A New Spelling of My Name (1982); a já citada compilação de artigos e discursos Sister Outsider, publicada pela primeira vez em 1984, entre outros. É relevante destacar que, em 1980, Lorde e a escritora Barbara Smith fundaram a editora Kitchen: Women of Color Press, com o objetivo de ampliar a publicação de obras de mulheres de cor. Entre os livros lançados pela editora podem ser mencionados This Bridge Called My Back: Writings by Radical Women of Color (1984), de Cherríe Moraga e Gloria Anzaldúa, Home Girls: A Black Feminist Anthology (1984), de Barbara Smith, e I Am Your Sister: Black Women Organizing Across Sexualities (1986), de Audre Lorde.

Sobre Angela Yvonne Davis, nascida em 1944, ela é ativista, escritora, professora aposentada e palestrante e tem contribuído amplamente para o debate acerca de temas como feminismo, racismo, luta anticapitalista e sistema prisional estadunidense ao longo dos anos. Suas publicações englobam obras de diferentes gêneros, entre as quais estão Angela Davis: An Autobiography (1974), Violence Against Women and the Ongoing Challenge to Racism (1985), Women, Culture E Politics (1990), Are Prisons Obsolete? (2003) e The Meaning of Freedom: And Other Difficult Dialogues (2012). Especificamente em relação a Women, Race E Class (1981), Davis faz um panorama dos movimentos feministas nos Estados Unidos desde o século

7 "As a Black poet and writer, I hate words that cancel my name and my history and the freedom of my future: I hate the words that condemn and refuse the language of my people in America."

8 Disponível em: <https://www.poetryfoundation.org/poets/audre-lorde>. Acesso em: o1 fev. 2019. 
XIX até a década de 8 o do século XX, mostrando o quanto as mulheres brancas e das classes média e alta envolvidas nesses movimentos, com foco no direito pelo sufrágio feminino, privilegiavam seus próprios interesses em detrimento das demandas de outras mulheres. Segundo Davis, "na condição de mulheres que sofriam com a combinação das restrições de sexo, raça e classe, elas [mulheres negras] tinham um poderoso argumento pelo direito ao voto. Mas o racismo operava de forma tão profunda no interior do movimento sufragista feminino que as portas nunca se abriram de fato às mulheres negras" (Davis, 2016: 149). Para além desse contexto, mesmo que não estivessem oficialmente submetidas ao sistema de escravidão após 1863, as mulheres negras continuaram a ser oprimidas em outras situações tais como as pouquíssimas oportunidades de trabalho, em geral no âmbito doméstico, e os abusos sexuais cometidos por seus patrões. Women, Race E Class, como o próprio título sugere, é uma importante contribuição para as discussões relativas ao feminismo e à interseccionalidade de raça, gênero e classe, tópico que será tratado adiante.

Além das autoras e obras mencionadas por Collins (2017), outra importante ativista, feminista e professora que merece ser destacada é bell hooks. Nascida em 1952, hooks adotou esse pseudônimo em homenagem à bisavó materna, grafando-o em letras minúsculas com o objetivo de chamar atenção para as suas ideias e não para a sua subjetividade. Uma de suas principais publicações é Ain't I a Woman? Black Women and Feminism, cujo título foi inspirado no discurso de Sojourner Truth anteriormente citado. Lançado em 1981, mas tendo seu primeiro rascunho escrito nos anos de 1970, o livro trata de questões como o impacto do racismo e do sexismo nas mulheres negras, a marginalização e inferiorização das mulheres negras, o sistema patriarcal e supremacista branco e o apagamento das reflexões sobre raça e classe no movimento feminista. Em uma de suas passagens, hooks ressalta que "nenhum outro grupo nos Estados Unidos tem tido a sua identidade tão socializada fora da existência quanto as mulheres negras...Quando se fala de pessoas negras, o foco tende a ser em homens negros; e quando se fala de mulheres, o foco tende a ser em mulheres brancas" (hooks, 2014: 7, tradução minha9). No conjunto de mais de 30 livros publicados até os dias de hoje, incluindo diferentes gêneros, encontramse Feminist Theory: From Margin to Center (1984), Talking Back: Thinking Feminist, Thinking Black (1989), Yearning: Race, Gender, and Cultural Politics (1990), Black Looks: Race and Representation (1992), Teaching to Transgress: Education as the Practice of Freedom (1994), Feminism is For Everybody: Passionate Politics (2000) e Writing Beyond Race: Living Theory and Practice (2013).

Após os estudos feministas negros ganharem reconhecimento acadêmico na década de 8 o do século XX - e mais uma vez é importante enfatizar o trabalho de autoras como June Jordan, Audre Lorde, Angela Davis e bell hooks nesse sentido nos anos de 1990, Kimberlé Crenshaw, advogada e professora universitária na área de

9 "No other group in America has so had their identity socialized out of existence as have black women... When black people are talked about the focus tends to be on black men; and when women are talked about the focus tends to be on white women." 
Estudos Raciais, publicou o texto "Mapping the Margins: Intersectionality, Identity Politics, and Violence against Women of Color" (1991), no qual defende a ideia de que as experiências das mulheres negras não podem ser consideradas de forma isolada nas categorias de raça e gênero, mas sim de modo interseccional. Collins, no livro Black Feminism Thought (2000), também trata dessa questão no capítulo "Towards a Politics of Empowerment". Em seu ponto de vista, a interseccionalidade é uma "[...] análise que afirma que os sistemas de raça, classe social, gênero, sexualidade, etnia, nação e idade formam-se mutuamente, construindo características de organização social que moldam as experiências das mulheres negras e, por sua vez, são moldados por mulheres negras" (Collins, 2000: 299, tradução minha ${ }^{10}$ ). Nesse caso, conforme Collins, os diferentes mecanismos de opressão operam simultaneamente na produção de injustiças sociais.

Além da interseccionalidade, a autora traz a concepção de matriz de dominação, segundo a qual, independentemente dos tipos específicos de opressão referentes a determinada situação, eles estão envolvidos em domínios de poder estruturais, disciplinares, hegemônicos e interpessoais. No domínio de poder estrutural, está implícita a ideia de que o modo pelo qual instituições sociais como educação, governo e mídia são organizadas tem um papel atuante na subordinação das mulheres negras ao longo dos tempos. Já o domínio de poder disciplinar se relaciona com a maneira como as instituições desenvolvem mecanismos de controle, supervisão e vigilância que visam a mascarar o racismo e o sexismo. Quanto ao domínio de poder hegemônico, ele visa a justificar as práticas dos outros domínios de poder: "ao manipular ideologia e cultura, o domínio hegemônico atua como uma ligação entre instituições sociais (domínio estrutural), suas práticas organizacionais (domínio disciplinar) e o nível de interação social diária (domínio interpessoal)" (Collins, 2000: 284, tradução minha ${ }^{11}$ ). O domínio de poder interpessoal funciona por meio de práticas rotineiras sobre como as pessoas tratam umas às outras. Ao mesmo tempo em que as experiências de vida de mulheres negras estadunidenses ilustram como esses quatro domínios de poder moldam a matriz de dominação, elas demonstram como esses domínios podem ser usados como motivação para ações de resistência e empoderamento. Com esse pensamento, Collins aponta para o fato de que, uma vez que a matriz de dominação está estruturada em categorias como raça, gênero, sexualidade e nação e atua através de domínios de poder que estão interconectados, a relação entre opressão e ativismo passa a se mostrar dotada de uma complexidade.

Ainda em Black Feminism Thought, no capítulo "Epistemologia feminista negra"12, Collins aborda o pensamento feminista negro nos Estados Unidos. De acordo

10 "[...] analysis claiming that systems of race, social class, gender, sexuality, ethnicity, nation, and age form mutually constructing features of social organization, which shape Black women's experiences and, in turn, are shaped by Black women."

11 "By manipulating ideology and culture, the hegemonic domain acts as a link between social institutions (structural domain), their organizational practices (disciplinary domain), and the level of everyday social interaction (interpersonal domain)."

12 Nesse caso, será utilizado o capítulo traduzido por Ana Claudia Jaquetto Pereira e publicado no livro Decolonialidade e pensamento afrodiaspórico (2018), organizado por Joaze Bernardino-Costa, Nelson Maldonado-Torres e Ramón Grosfoguel. 
com a autora, diante da supressão das mulheres negras no âmbito de instituições sociais coordenadas majoritariamente por homens brancos, elas procuraram outros meios como a música e a literatura para que suas vozes pudessem ser ouvidas e, posteriormente, passaram a utilizar os espaços da universidade para a divulgação e validação de ideias feministas. No entanto, essas mulheres têm que encarar o desafio de lidar com uma estrutura de conhecimentos considerados predominantes e ligados a um sistema branco e patriarcal. Além disso, "acadêmicas negras que persistem na tentativa de rearticular um ponto de vista de mulheres negras também se deparam com a potencial rejeição, em termos epistemológicos, daquilo que afirmam ser conhecimento" (Collins, 2018: 145). Ainda assim, as experiências de vida e visões de mundo das mulheres afro-americanas servem de base para a proposição do que Collins denomina de epistemologia feminista negra, composta por quatro dimensões. A primeira dimensão é a valorização da sabedoria, uma vez que ela é necessária para a própria sobrevivência das mulheres negras nos Estados Unidos; a segunda é o diálogo com outros membros da comunidade, vistos como importantes para a construção de novos conhecimentos; a terceira é a ética do cuidado, na qual fatores como a expressividade pessoal, as emoções e a empatia são fundamentais no processo de validação do conhecimento; a quarta é a ética da responsabilidade pessoal, a partir da qual espera-se que o indivíduo tenha relação direta com suas próprias ideias e se responsabilize pelas suas afirmações. Com isso, "a existência do ponto de vista das mulheres negras que utilizam a epistemologia feminista negra desafia o que é normalmente tomado como verdade e, ao mesmo tempo, questiona o processo através do qual tal verdade é produzida” (Collins, 2018: 167).

Levando-se em consideração a relevância do pensamento de intelectuais afro-americanas como June Jordan, Audre Lorde, Angela Davis, bell hooks e Patricia Hill Collins, para além do contexto estadunidense, em um mundo globalizado na contemporaneidade, surgem os seguintes questionamentos sobre a divulgação de suas vozes por meio da tradução: Que obras e textos têm sido traduzidos e publicados no Brasil? Quem são os/as tradutores/as? Quais são as editoras e periódicos acadêmicos envolvidos? Quais são os contextos de publicação? Nesse sentido, na seção seguinte, serão apresentados um breve panorama da produção não-ficcional das referidas autoras que se encontra disponível e, após isso, uma discussão sobre esse quadro no âmbito do polissistema literário brasileiro.

\section{Breve panorama da produção de feministas afro-americanas traduzida no Brasil}

Nesta seção, serão fornecidos dados das traduções brasileiras de obras e textos não-ficcionais de pensadoras afro-americanas, contendo os nomes das autoras em ordem alfabética, os anos de publicação (em ordem cronológica), os títulos das obras traduzidas, os nomes dos/as tradutores/as, os locais de publicação, as editoras e os 
periódicos, além dos títulos e anos da primeira edição dos livros e textos no contexto de partida. Por fim, será proposta uma análise do panorama em questão.

\section{Obras completas:}

COLLINS, Patricia Hill. (2019 - a ser lançado'³). Pensamento feminista negro. Sem nome do/a tradutor/a. São Paulo: Boitempo. (Tradução de Black Feminist Thought: Knowledge, Consciousness, and the Politics, 1990)

DAVIS, Angela. (2009). A democracia da abolição: para além do império, das prisões e da tortura. Tradução de Artur Neves Teixeira. Rio de Janeiro: Difel. (Tradução de Abolition Democracy: Beyond Empire, Prisons, and Torture, 2006)

DAVIS, Angela. (2016). Mulheres, raça e classe. Tradução de Heci Regina Candiani. São Paulo: Boitempo. (Tradução de Women, Race E Class, 1981)14

DAVIS, Angela. (2017). Mulheres, cultura e política. Tradução de Heci Regina Candiani. São Paulo: Boitempo. (Tradução de Women, Culture E Politics, 1989)

DAVIS, Angela. (2018). A liberdade é uma luta constante. Tradução de Heci Regina Candiani. São Paulo: Boitempo. (Tradução de Freedom is a Constant Struggle: Ferguson, Palestine, and the Foundations of a Movement, 2015)

DAVIS, Angela. (2018). Estarão as prisões obsoletas? Tradução de Mariana Vargas. Rio de Janeiro: Difel. (Tradução de Are Prisons Obsolete? 2003)

DAVIS, Angela. (2019). Uma autobiografia. Tradução de Heci Regina Candiani. São Paulo: Boitempo. (Tradução de An autobiography, 1974)

hooks, bell. (2013). Ensinando a transgredir: a educação como prática da liberdade. Tradução de Marcelo Brandão Cipola. São Paulo: WMF Martins Fontes. (Tradução de Teaching to Transgress: Education as the Practice of Freedom, 1994)

hooks, bell. (2018). O feminismo é para todo mundo: políticas arrebatadoras. Tradução de Ana Luiza Libânio. Rio de Janeiro: Rosa dos Tempos. (Tradução de Feminism is for Everybody: Passionate Politics, 2000)

13 Esse livro será lançado ainda no ano de 2019. Não foi divulgado, até o momento, o nome do/da tradutor/a.

14 Para informações sobre essa tradução, ver o artigo de minha autoria "Diáspora negra em contexto de tradução: discutindo a publicação de Mulheres, raça e classe, de Angela Davis, no Brasil" na revista Trabalhos em Linguística Aplicada (2018), v. 57, n. 1, p. 205-228. 
hooks, bell. (2019). Olhares negros: raça e representação. Tradução de Stephanie Borges. São Paulo: Elefante. (Tradução de Black Looks: Race and Representation, 1992)

hooks, bell. (2019). Erguer a voz: pensar como feminista, pensar como negra. Tradução de Catia Maringolo. São Paulo: Elefante. (Tradução de Talking Back: Thinking Feminist, Thinking Black, 1989)

\section{Textos publicados em/como livros:}

COLLINS, Patricia Hill. (2015). "Em direção a uma nova visão: raça, classe e gênero como categorias de análise e conexão". Tradução de Júlia Clímaco. In: MORENO, Renata (Org.). Reflexões e práticas de transformação feminista. São Paulo: SOF, 2015. p. 13-42. Disponível em: <https://br.boell.org/sites/default/files/ reflexoesepraticasdetransformacaofeminista-1.pdf >. Acesso em: o1 fev. 2019. (Tradução da palestra "Toward A New Vision: Race, Class and Gender as Categories of Analysis and Connection", 1989, realizada no Center for Research on Women, Memphis State University)

COLLINS, Patricia Hill. (2017). "Epistemologia feminista negra". Tradução de Ana Claudia Jaquetto Pereira. In: BERNARDINO-COSTA, Joaze; MALDONADOTORRES, Nelson; GROSFOGUEL, Ramón. (Orgs.). Decolonialidade e pensamento afro-diaspórico. Belo Horizonte: Autêntica. p. 139-17o. (Tradução do capítulo "Black Feminist Epistemology", do livro Black Feminist Thought, 2000, p. 251-271)

DAVIS, Angela. (2018). Educação e libertação: a perspectiva das mulheres negras. Tradução de Heci Regina Candiani. São Paulo: Boitempo. E-book Kindle. (Tradução do capítulo "Education and Liberation: Black Women's Perspective", do livro Women, Race \& Class, 1981, p. 99-109)

DAVIS, Angela. (2018). Estupro, racismo e o mito do estuprador negro. Tradução de Heci Regina Candiani. São Paulo: Boitempo. E-book Kindle. (Tradução do capítulo "Rape, Racism and the Myth of the Black Rapist", do livro Women, Race \& Class, 1981, p. 172-201)

DAVIS, Angela. (2018). Racismo no movimento sufragista feminino. Tradução de Heci Regina Candiani. São Paulo: Boitempo. E-book Kindle. (Tradução do capítulo "Racism in the Woman Suffrage Movement”, do livro Women, Race E Class, 1981, p. 70-86) 
hooks, bell. (2017). "O olhar oposicional: espectadoras negras". Tradução de Raquel D’Elboux Couto Nunes. In: BRANDÃO, Izabel; CAVALCANTI, Ildney; COSTA; Claudia de Lima; LIMA, Ana Cecília Acioli. (Orgs.). Traduções da Cultura: perspectivas críticas feministas (1970-2010). Florianópolis: EDUFAL; Editora da UFSC. p. 484-509. (Tradução do capítulo “The Oppositional Gaze: Black Female Spectators”, do livro Black Looks: Race and Representation, 1992, p. 115-131)

\section{Textos publicados em periódicos acadêmicos:}

COLLINS, Patricia Hill. (2016). "Aprendendo com a outsider within: a significação sociológica do pensamento feminista negro". Tradução de Juliana de Castro Galvão e revisão de Joaze Bernardino Costa. Sociedade e Estado, n. 1: 31, p. 99-127, jan.-abr. Disponível em: <http://www.scielo.br/pdf/se/v31n1/o102-6992-se-31-01-ooo99.pdf>. Acesso em: o1 fev. 2019. (Tradução do artigo "Learning From the Outsider Within: The Sociological Significance of Black Feminist Thought”, publicado em Social Problems, 1986, n. 6: 33, p. 14-32, Oct.-Dec.)

COLLINS, Patricia Hill. (2017). "O que é um nome? Mulherismo, feminismo negro e além disso”. Tradução de Angela Figueiredo e Jesse Ferrell. Cadernos Pagu, n. 51, s.n.p., dez. Disponível em: <http://www.scielo.br/pdf/cpa/n51/18o9-4449cpa-18094449201700510018.pdf> . Acesso em: o1 fev. 2019. (Tradução do ensaio "What's in a Name? Womanism, Black Feminism, and Beyond", publicado em The Black Scholar, 1996, n. 26: 1, p. 9-17)

COLLINS, Patricia Hill. (2017). "Se perdeu na tradução? Feminismo negro, interseccionalidade e política emancipatória”. Tradução de Bianca Santana. Parágrafo, São Paulo, n. 1: 5, p. 7-17, jan.-jun. Disponível em: <http://revistaseletronicas.fiamfaam. br/index.php/recicofi/article/view/559/506>. Acesso em: o1 fev. 2019. (Tradução da palestra "Lost in Translation? Black Feminism, Social Justice and Intersectionality", 2012, realizada no Plenary Address, Collegium of Black Women Philosophers, Pennsylvania State University)

DAVIS, Angela; DENT, Gina. (2003). "A prisão como fronteira: uma conversa sobre gênero, globalização e punição". Tradução de Pedro Diniz Bennaton e revisão de Susana Bornéo Funck e José Renato de Faria. Estudos Feministas, n. 11:2, p. 523-531, jul.-dez. Disponível em: <http://www.scielo.br/pdf/ref/vıın2/19136.pdf>. Acesso em: o1 fev. 2019. (Tradução do diálogo "Prison as a Border: A Conversation on Gender, Globalization, and Punishment", publicado em Signs: Journal of Women in Culture and Society, 2001, n. 4: 26, p. 1235-1241) 
hooks, bell; STEINEM, Gloria; WOLF, Naomi. (1994). "Vamos falar a verdade sobre o feminismo”. Tradução de Marcos Santarrita. Estudos Feministas, n. 1, p. 162-176, jan-jun. Disponível em: <https://periodicos.ufsc.br/index.php/ref/article/view/16295/14836>. Acesso em: o1 fev. 2019. (Tradução do debate "Let's Get Real About Feminism: The Backlash, the Myths, the Movement”, da revista Ms, 1993, p. 34-43, set.-oct.)

hooks, bell. (1995). “Intelectuais negras”. Tradução de Marcos Santarrita. Estudos Feministas, n. 2, p. 464-478, jul.-dez. Disponível em: <https://periodicos.ufsc.br/ index.php/ref/article/view/16465/15035>. Acesso em: o1 fev. 2019. (Tradução do capítulo "Black Women Intellectuals", do livro Breaking Bread: Insurgent Black Intellectual Life, 1991, p. 147-165)

hooks, bell. (2008). “Linguagem: ensinar novas paisagens/novas linguagens”. Tradução de Carlianne Paiva Gonçalves, Joana Plaza Pinto e Paula de Almeida Silva. Estudos Feministas, n. 3: 16, p. 857-864, dez. Disponível em: <http://www.scielo.br/pdf/ref/ v16n3/o7.pdf>. Acesso em: o1 fev. 2019. (Tradução do capítulo "Language. Teaching New Worlds, New Words", do livro Teaching to Transgress: Education as Practice of Freedom, 1994, p. 167-175)

hooks, bell. (2015). "Escolarizando homens negros”. Tradução de Alan Augusto Ribeiro e Keisha-Khan Y. Perry. Estudos Feministas, n. 3: 26, p. 677-689, dez. Disponível em: <http://www.scielo.br/pdf/ref/v23n3/o104-026X-ref-23-03-00677.pdf>. Acesso em: o1 fev. 2019. (Tradução do capítulo "Schooling Black Males", do livro We Real Cool: Black Men and Masculinity, 2004, p. 33-45)

hooks, bell. (2015). "Mulheres negras: moldando a teoria feminista". Tradução de Roberto Cataldo Costa e revisão de Flávia Biroli. Revista Brasileira de Ciência Política, n. 16, p.193-210, abr. Disponível em: <http://www.scielo.br/pdf/rbcpol/n16/o103-3352rbcpol-16-oo193.pdf>. Acesso em: o1 fev. 2019. (Tradução do capítulo "Black Women: Shaping Feminist Theory", do livro Feminist Theory: From Margin To Center, 20oo, p. 1-15)

O panorama apresentado conduz a algumas reflexões sobre a tradução de obras e textos não-ficcionais de intelectuais afro-americanas no Brasil. No que tange à publicação de livros completos, foram encontrados seis de Angela Davis e quatro de bell hooks, sendo que nem todos tratam especificamente de questões de raça e gênero. Além disso, está previsto o lançamento de um dos livros de Patricia Hill Collins. Quanto a June Jordan e Audre Lorde, verificou-se uma ausência de obras na íntegra traduzidas no contexto brasileiro. Sobre as editoras, a Difel tem em seu catálogo livros de referência e ensaios na área das ciências humanas, bem como biografias de grandes personalidades, tendo sido fundada em 1999 após pedidos de leitores/as, 
sobretudo do meio acadêmico. A Boitempo, por sua vez, estabeleceu-se no mercado editorial em 1995 e tem como foco a publicação de livros no âmbito das ciências humanas, abordando temáticas como indústria cultural, capitalismo, comunismo, marxismo e questões de gênero. A WMF Martins Fontes iniciou seus trabalhos na década de 1970, com o objetivo de divulgar obras nos campos de filosofia, sociologia, psicologia e literatura. Já a Rosa dos Tempos, como foi mencionado anteriormente, vem se dedicando à propagação de escritas sob a ótica feminista desde 1990, quando foi inaugurada. Quanto à Elefante, fundada em 2011, seu propósito é publicar livros que tenham relevância social, política e cultural.

Com relação às autoras Angela Davis e bell hooks, pode-se notar que, mesmo que elas tenham tido seus primeiros livros publicados no contexto estadunidense durante os anos de 1970, no Brasil, isso só começou a ser feito recentemente. Tal fato pode estar relacionado ao reconhecimento, por parte de editoras como a Boitempo, de que existe um público leitor, no polissistema literário brasileiro, que se interessa por escritas afrodiaspóricas que abordem questões de gênero e raça. Para ilustrar essa ideia, Maurício Meireles traz a seguinte afirmação sobre o livro Mulheres, raça e classe, no texto "Do comercial ao 'cabeça', editoras do país exploram livros feministas" (2017), publicado no jornal Folha de São Paulo:

De todo modo, a expansão dos estudos de gênero no meio universitário ainda que tímida - favorece livros com outro perfil. A editora de esquerda Boitempo, que publica obras do segmento, viu "Mulher, raça e classe", da ativista negra Angela Davis, vender mais que o esperado, 14 mil até agora. A tiragem inicial apostava modestos 6.ooo. (Meireles, 2017)

A respeito dos/as tradutores/as, destaca-se a sua variabilidade nas publicações, sendo que a maior parte é formada por mulheres. Especificamente no caso das obras de Angela Davis lançadas pela editora Boitempo, tem-se mantido o trabalho da mesma tradutora, Heci Regina Candiani, que é jornalista, cientista social e doutora em Ciências Sociais pela Unicamp.

Quanto aos textos publicados como livros, é interessante notar que a Boitempo lançou três capítulos de Mulheres, raça e classe como e-books. Nesse caso, o/a leitor/a pode ter acesso a partes da obra em questão, pagando um preço mais baixo e utilizando o meio virtual. Sobre os textos publicados em livros, foram encontrados dois de Patricia Hill Collins e um de bell hooks. Enquanto um dos textos de Collins se situa no contexto de uma publicação voltada para o pensamento decolonial e afrodiaspórico, o outro está presente em uma obra, disponível online, sobre feminismos em geral. O texto de hooks, por sua vez, encontra-se em uma coletânea de escritas traduzidas, vinculadas a uma conjuntura feminista ampla e diversa. Sendo assim, nenhum dos textos em questão está inserido em um livro dedicado especificamente à interseccionalidade de raça e gênero. Além disso, todos eles foram publicados há poucos anos. Ainda nesse contexto, estão ausentes obras e textos de June Jordan e Audre Lorde. Sobre as editoras, a SOF - Sempreviva Organização Feminista - é uma organização não-governamental que faz parte do movimento de mulheres no Brasil e em âmbito internacional, com atuação desde os 
anos de 1980. A Autêntica foi fundada em 1997, para atender ao público acadêmico. Com esse mesmo objetivo, a EDUFAL e a editora da UFSC têm publicado obras em diferentes áreas do conhecimento. Quanto às tradutoras, todas elas têm no mínimo a titulação de mestre, sendo que, no caso de Ana Claudia Jaquetto Pereira, doutora em Ciência Política pela UERJ, ela desenvolve pesquisas com temáticas relacionadas a raça e gênero.

As traduções de textos publicados em periódicos acadêmicos proporcionam uma disponibilidade maior das escritas de Angela Davis, bell hooks e Patricia Hill Collins no Brasil. Ao mesmo tempo, reforça-se a invisibilidade das vozes de June Jordan e Audre Lorde, cujas escritas não foram observadas no presente contexto. Nesse cenário, destacam-se aspectos como: os textos de hooks têm sido traduzidos em maior número e por um maior período de tempo; o texto de Davis, em conjunto com Gina Dent, foi o único a ser traduzido; os textos de Collins têm sido traduzidos de uns anos para cá; a maior parte dos textos traduzidos dessas autoras aborda questões feministas. Quanto aos periódicos envolvidos, Sociedade e Estado (UnB) é dirigido a publicações na área de Ciências Sociais; Revista Brasileira de Ciência Política (UnB), como o próprio título sugere, divulga textos na área de ciência política; Parágrafo (FIAM-FAAM) tem como foco artigos pertinentes ao campo do jornalismo. Já Cadernos Pagu (Unicamp) e Estudos Feministas (UFSC) são periódicos interdisciplinares voltados aos estudos de gênero. Sendo assim, percebe-se o quanto periódicos como os citados têm contribuído para a divulgação do pensamento de intelectuais afro-americanas no Brasil a partir da tradução. Acerca dos/as tradutores/ as, eles/as são variados/as e, em sua maioria, tiveram suas traduções feitas e/ou revisadas em conjunto com outras pessoas.

Em geral, percebe-se que está havendo um crescimento de publicações de textos traduzidos de Angela Davis, bell hooks e Patricia Hill Collins por editoras como a Boitempo, que tem publicado traduções de livros de Davis e lançará a tradução de uma das obras de Collins ainda em 2019. Além disso, os periódicos acadêmicos têm exercido um papel importante na divulgação do trabalho das intelectuais em questão. Mesmo diante desse cenário que vem se ampliando ao longo dos anos, ainda há pouco material de pensadoras afro-americanas traduzido no Brasil. E quais poderiam ser os motivos para isso?

Os pensamentos de Toury (1995) de que a tradução é um fenômeno próprio da cultura-meta, que determina sua função, seu processo e seu produto, e de Bassnett \& Lefevere (1990), para quem a tradução é uma reescrita submetida a questões culturais, sócio-históricas, ideológicas e de patronagem, ajudam em uma reflexão sobre o cenário apontado. Soma-se a isso esta declaração de Sonia E. Alvarez e Claudia de Lima Costa, no texto "A circulação das teorias feministas e os desafios da tradução" (2013):

É bem sabido que os textos não viajam através de contextos linguísticos sem um 'visto'. Seu deslocamento pode acontecer somente se também houver um aparato material organizando sua tradução, publicação e circulação. Este aparato - que, ao mesmo tempo que é constituído pelos contextos de recepção, também os constitui 
- influencia de maneira significativa quais teorias/textos são traduzidos e (re) significados para ajustar-se melhor às agendas intelectuais locais. (Alvarez; Costa, 2013: 581)

Sendo assim, a escassa visibilidade das escritas não-ficcionais de intelectuais afro-americanas no Brasil pode estar ligada a fatores como a suposição de que há um número reduzido de leitores/as com demanda para textos vinculados ao feminismo negro, à necessidade de concessão de direitos autorais, à matriz de dominação proeminente em determinadas instituições, marcadas pelo racismo estrutural, entre outros. Percebendo essa falta de abertura do mercado editorial brasileiro para a tradução de textos de autoras negras, estadunidenses e de outras nacionalidades, e enxergando a possibilidade de utilizar espaços alternativos que resistam a esse mecanismo de poder, alguns sites como "Despatriarcalize"15, "Traduzidas"16 e "Preta, nerd \& Burning Hell” ${ }^{17}$ têm contribuído para a ampliação dessas vozes por meio da tradução.

Quanto aos referidos sites, o "Despatriarcalize" se propõe como um espaço para a divulgação de traduções de textos feministas, definindo-se da seguinte forma: "Somos as mulheres que os homens nos alertaram". Os textos traduzidos disponíveis, englobando o período de fevereiro de 2014 a abril de 2015, são trechos e capítulos de livros, artigos e ensaios. Entre eles encontram-se dois textos de Audre Lorde: o discurso "As ferramentas do mestre nunca vão desmantelar a casa-grande", realizado em uma conferência feminista na universidade de Nova York em 1984 e o ensaio "Não há hierarquias de opressão", parte de um capítulo do livro Eu sou sua irmã: escritos coletados e não-publicados de Audre Lorde, lançado em 2009. Enquanto o primeiro texto é uma crítica de Lorde ao fato de ela ter sido uma negra lésbica feminista convidada a falar no único painel em que a perspectiva das negras feministas lésbicas esteve representada, no contexto de um país onde racismo, sexismo e homofobia são inseparáveis, o segundo texto reflete o que se encontra em seu próprio título. Nesse caso, os textos traduzidos de Lorde apontam para a interseccionalidade de raça e gênero no conjunto de múltiplas opressões. Eles foram publicados no site "Despatriarcalize" por Fabiana Serra e não há informação sobre quem os traduziu.

Já o site "Traduzidas" apresenta "traduções feministas clandestinas: feminismos de cor, lesbianos, piratarias, feministas lésbicas negras, pessoas cuír/queer de cor (queer of color people - QCP) y más!", feitas por Tatiana Nascimento. Nascimento é tradutora, poeta, editora e fundadora da Padê editorial, que produz artesanalmente livros de escritoras negras e LGBT, além de doutora em Estudos da Tradução pela UFSC. Sua tese de doutorado, intitulada "Letramento e tradução no espelho de Oxum: teoria lésbica negra em auto/re/conhecimentos” e defendida em 2014, traz importantes contribuições para os estudos que relacionam questões de tradução,

15 Disponível em: <https://catsfordestroypatriarchy.wordpress.com/>. Acesso em: 04 fev. 2019. 16 Disponível em: <https://traduzidas.wordpress.com/about/>. Acesso em: 04 fev. 2019.

17 Disponível em: <http://www.pretaenerd.com.br/p/blog-page.html>. Acesso em o4 fev. 2019. 
raça e gênero, visto que apresenta propostas de traduções de textos das feministas negras lésbicas estadunidenses Audre Lorde, Cheryl Clarke e Doris Davenport.

O site “Traduzidas" contém textos publicados entre janeiro de 2011 e março de 2018, os quais abrangem artigos, ensaios, poemas e entrevistas. Entre eles podem ser citados alguns de autoras afro-americanas: o poema "Mulher de duas cabeças", de Doris Davenport, o ensaio "Mas algumas de nós somos lésbicas corajosas: a ausência da literatura negra lésbica” (2005), de Jewelle Gomez e um trecho da entrevista em vídeo de Toni Morrison em que ela trata de questões de raça em sua escrita. O site também apresenta textos traduzidos de Audre Lorde, sendo eles o poema "Mulher", os ensaios "Poesia não é um luxo" (1977), "Usos do erótico: o erótico como poder" (1984) e "Autodefinição e minha poesia" (2009), além do discurso "As ferramentas do sinhô nunca vão derrubar a casa-grande", o mesmo que foi traduzido e disponibilizado no site "Despatriarcalize", como mencionado anteriormente. É interessante observar que, nesse caso, a tradutora optou por não traduzir o termo "master" por "mestre". Ao fazer isso, ela silenciou a ideia de poder contida nesse termo, optando por substituí-lo pelo vocábulo "sinhô", forma de tratamento que as pessoas escravizadas utilizavam para se referir aos donos das terras nas quais eram obrigados a trabalhar durante o período colonial brasileiro. Ao fazer isso, Nascimento demonstra ter realizado uma “tradução ativista”. Segundo Maria Tymoczko, professora de Estudos da Tradução na universidade de Massachussetts, "[...] as traduções ativistas são performativas - elas são atos dentro de campos mais amplos de programas de ação ideológicos e políticos específicos e sua eficácia é uma função de sua natureza performativa" (Tymoczko, 2010: 252, tradução minha) $)^{18}$.

Diferentemente dos sites "Despatriarcalize" e "Traduzidas", o site "Preta, Nerd \& Burning Hell” não é um site específico de traduções, mas sim "um espaço virtual onde é possível discutir um modo de consumo (nerdiandade) tendo em vista a simultaneidade dos recortes de raça, gênero, classe", bem como "explorar os caminhos que têm sido negados historicamente à população negra, em especial, às mulheres Negras”. Entre as traduções disponibilizadas no site, entre janeiro de 2015 a fevereiro de 2017 , encontra-se "Idade, raça, classe e sexo: mulheres redefinindo a diferença", de Audre Lorde, que havia sido publicado no contexto estadunidense como um capítulo do livro Sister Outsider (1984). O nome de quem fez essa tradução está ausente.

Portanto, diante desse breve panorama de obras e textos não-ficcionais de intelectuais afro-americanas, observa-se que, embora a publicação de traduções desse material ainda seja pequena, existe um movimento de resistência, a partir da produção de traduções que se autointitulam “clandestinas”. E é por causa de movimentos como esse que vozes como as de Audre Lorde ultrapassam as barreiras do silenciamento que ainda imperam no polisistema literário brasileiro, marcado pela matriz de dominação, especialmente no que diz respeito ao grande mercado editorial.

18 "[...] activist translations are performatives - they are acts within broader fields of specific political and ideological programs of action and their effectiveness is a function of their performative nature." 


\section{Considerações finais}

Segundo Even-Zohar (2005), Bassnett \& Lefevere (1990) e Toury (1995), a tradução é muito mais do que um processo de transferência de material linguístico de uma língua para outra, na medida em que nela estão envolvidos aspectos culturais, sociais, históricos e econômicos. Além disso, o sistema de chegada tem um papel atuante na seleção dos textos que serão traduzidos, na definição dos/as tradutores/as que serão responsáveis por esse processo e na configuração do produto final. Tendo em vista todo esse mecanismo de poder, este artigo buscou verificar que obras e textos não-ficcionais de intelectuais afro-americanas estão disponíveis no polissistema literário brasileiro.

Para tanto, foram feitas discussões acerca do feminismo negro estadunidense e sua luta contra o racismo e o sexismo, mesmo dentro do movimento feminista, liderado por mulheres brancas das classes média e alta. Nesse sentido, o discurso de Sojourner Truth, proferido em 1851, foi extremamente importante para o reconhecimento de demandas específicas das mulheres negras, inspirando o trabalho de outras pensadoras e ativistas afro-americanas como June Jordan, Audre Lorde, Angela Davis, bell hooks e Patricia Hill Collins nos séculos XX e XXI. Na produção dessas autoras, é reforçada a ideia de que o feminismo negro tem suas especificidades em comparação a outros tipos de feminismo. Isso porque as mulheres negras sofrem uma dupla opressão - a de raça e a de gênero - que se interrelacionam. Além disso, Collins, especificamente, enfatiza a atuação de uma matriz de dominação sobre a vida de mulheres afro-americanas. Essas, por sua vez, ao estarem submetidas aos diferentes domínios desse sistema hegemônico, têm demonstrado um movimento de resistência e empoderamento.

Em seguida, foi apresentado um breve panorama de obras e textos nãoficcionais das autoras mencionadas que foram traduzidos no Brasil e publicados por editoras e periódicos acadêmicos. A partir das observações realizadas, levando-se em conta os diferentes dados coletados, percebeu-se que ainda há pouco material traduzido. Por um lado, foram encontrados alguns livros e textos de Angela Davis, bell hooks e Patricia Hill Collins. Por outro lado, no que se refere a June Jordan e Audre Lorde, não foi localizada nenhuma tradução de livros e textos de suas autorias publicados por editoras ou periódicos acadêmicos. Tendo em vista essa ausência, sites como "Despatriarcalize", “Traduzidas" e "Preta, nerd \& Burning Hell” vem disponibilizando textos de intelectuais feministas negras por meio da tradução.

Mesmo que se tratem de "traduções clandestinas", elas têm exercido uma função ativista no que diz respeito à promoção de vozes como as de Lorde, hooks e Davis e, com isso, contribuído de forma muito importante para a divulgação de obras de feministas afro-americanas no Brasil. Mas até quando será preciso quebrar barreiras editoriais, até mesmo burlando leis como a de direitos autorais, para que sejam visibilizadas as produções de autoras negras? Diante desse cenário, espera-se que o espaço da tradução possa ser utilizado cada vez mais, em diferentes meios, 
para fazer com que epistemologias feministas negras, historicamente suprimidas e marginalizadas, sejam amplamente divulgadas. E, para além disso, que elas contribuam para uma ruptura de paradigmas racistas e sexistas, a partir de uma perspectiva anti-patriarcalista e antirracista.

\section{Referências Bibliográficas}

ALVAREZ, Sonia E.; COSTA, Claudia de Lima. (2013). "A circulação das teorias feministas e os desafios da tradução". Estudos feministas, n. 2, 21: p. 579-586, mai-ago.

AMORIM, Lauro Maia. (2012). "O papel da tradução na construção da identidade da literatura afro-americana no Brasil”. Revista do GEL, n. 1, 9: p. 107-134.

BASSNETT, Susan \& LEFEVERE, André. (1990). “Introduction: Proust's Grandmother and the Thousand and One Nights: The 'Cultural Turn' in Translation Studies". In: BASSNETT, Susan \& LEFEVERE, André (eds.). Translation, History and Culture. London: Pinter Publishers. p. 1-13.

BASSNETT, Susan. (1992). “Writing In No Man's Land: Questions of Gender and Translation”. Ilha do Desterro, n. 28, 1: p. 63-73, jul-dez.

COLLINS, Patricia Hill. (200o). “Towards a Politics of Empowerment”. In: COLLINS, Patricia Hill. Black Feminism Thought. Nova York/ Londres: Routledge. p. 273-29o.

COLLINS, Patricia Hill. (2017). "Se perdeu na tradução? Feminismo negro, interseccionalidade e política emancipatória”. Tradução de Bianca Santana. Parágrafo, n. 1, 5: p. 7-17, jan-jun.

COLLINS, Patricia Hill. (2018). "Epistemologia feminista negra". Tradução de Ana Claudia Jaquetto Pereira. In: BERNARDINO-COSTA, Joaze; MALDONADO-TORRES, Nelson; GROSFOGUEL, Ramón. (orgs.). Decolonialidade e pensamento afrodiaspórico. Belo Horizonte: Autêntica Editora. p. 139-170.

DAVIS, Angela. (2016). Mulheres, raça e classe. Tradução de Heci Regina Candiani. São Paulo: Boitempo.

DESPATRIARCALIZE. Disponível em: <https://catsfordestroypatriarchy.wordpress. com/>. Acesso em: 04 fev. 2019.

EVEN-ZOHAR, Itamar. (2005). "Polysystem Studies: Polysystem Theory (revised)". In: EVEN-ZOHAR, Itamar. Papers in Culture Research. Tel-Aviv: Porter Chair of Semiotics. p. 1-11. 
GÓIS, Edma de; LUNA, Danielle de. (2018) "Literatura e ativismo para segurar o mundo: entrevista com Patricia Hill Collins”. Suplemento Pernambuco, n. 153: p. 8-9.

HATTNHER, Álvaro. (1998). "Presença de autores afro-americanos no Brasil: as traduções”. Crop, n. 4-5, 1: p. 297-313.

hooks, bell. (2014). Ain't I a Woman? Black Women and Feminism. Nova York/ Londres: Routledge.

JORDAN, June. (1981). Civil Wars. Boston: Beacon Press.

LEFEVERE, André. (1992). Translation, Rewriting and the Manipulation of the Literary Fame. 1a ed. London/New York: Routledge.

LORDE, Audre. (2007). Sister Outsider. Berkeley: Crossing Press.

MEIRELES, Maurício. (2017). Do comercial ao 'cabeça', editoras do país exploram livros feministas. Folha de São Paulo. Disponível em: <http://www1.folha.uol.com. br/ilustrada/2017/o4/1873710-do-comercial-ao-cabeca-editoras-do-pais-exploramonda-feminista.shtml>. Acesso em: 02 fev. 2019.

NASCIMENTO, Tatiana. (2017). “Quem nomeou essas mulheres 'de cor'? Políticas feministas de tradução que mal dão conta das sujeitas negras traduzidas”. Translatio, n. 13: 127-142.

POETRY FOUNDATION. Audre Lorde. Disponível em: <https://www. poetryfoundation.org/poets/audre-lorde>. Acesso em: o1 fev. 2019.

PRETA, NERD \& BURNING HELL. Disponível em: <http://www.pretaenerd.com. br/p/blog-page.html>. Acesso em o4 fev. 2019.

RIBEIRO, Djamila. (2017). O que é lugar de fala? Belo Horizonte: Letramento.

SHUTTLEWORTH, Mark. (1998). "Polysystem Theory". In: BAKER, Mona (ed.). Encyclopedia of Translation Studies. Manchester, UK: St. Jerome. p. 176-179.

SILVA, Luciana de Mesquita. (2018). "Diáspora negra em contexto de tradução: discutindo a publicação de Mulheres, raça e classe, de Angela Davis, no Brasil". Trabalhos em Linguística Aplicada, n. 1, 57: 205-228.

TOURY, Gideon. (1995). Descriptive Translation Studies and Beyond. Amsterdam/ Philadelphia: John Benjamins. 
TRADUZIDAS. Disponível em: <https://traduzidas.wordpress.com/about/>. Acesso em: 04 fev. 2019.

TYMOCZKO, Maria. (2007). Enlarging Translation, Empowering Translators. Manchester: St. Jerome.

TYMOCZKO, Maria. (2010). Translation, Resistance, Activism. Amherst and Boston: University of Massachusetts Press. 